\title{
The Identification of Research Priority in The Field of Food Security
}

\author{
Budi Triyono*, Chichi Sinthia Laksani, Muhammad Zulhamdani, Irene \\ Muflikh Nadhiroh, and Lutfah Ariana
}

Center for Science and Technology Development Studies-Indonesia Institute of Sciences

(Received September 24, 2018; Accepted October 25, 2018; published December 8, 2018)

\begin{abstract}
The development of food security in Indonesia still faces various problems. Dealing with those problems, the role of research and development institutions such as the Indonesia Institute of Sciences (LIPI) is needed. LIPI as a government $R \& D$ institution is expected not only to produce knowledge, but also to play an active role in solving various problems of the nation including in the field of food security. The results of the evaluation of LIPI's activities show that it has produced significant and strategic research outputs. However, only a few have been successfully implemented to solve food problems. Therefore, a study of Research Priority Setting (RPS) is needed so that the LIPI research activities program in the future will produce more research outputs that play a role in providing solutions in this food sector. The purpose of this RPS study is to provide direction so that LIPI research in the future can contribute more to solving problems in the food sector. This study starts from the activity stage to identify strategic issues that need to be resolved through $R \& D$ activities. This identification activity is carried out through a round table discussion involving stakeholders. The next stage is to determine researches that need to be prioritized by LIPI in the next five years using the Delphi method. From the study, it is concluded that in the next five years LIPI's R \& D activities should be focused on: (1) the development of biological organic fertilizer, (2) the development of local food materials, (3) the development of Germplasm, (4) the functional food development, and (5) the development of modern agriculture.
\end{abstract}

Keywords : research priority, food security, LIPI, fuctional food, local food

JEL Classification: D24, L26, Q12

\section{INTRODUCTION}

At present, Indonesia is faced with a growing population. This condition results in an increase of food demand. Statistical data show that middle to upper income groups are increasing, which has an impact on food demand. Data from BAPPENAS (2016) show that Indonesian rice consumption currently tended to decline. Conversely, there was an increase in consumption of beef and fish. When viewed from the side of consumption expenditure, data show that consumption expenditure in serelia has decreased. Meanwhile expenditures for consumption of protein (meat and fish), vitamins (fruits and vegetables) and processed foods have

\footnotetext{
* Corresponding author email: budi_triyono012@yahoo.co.id, ISSN 2615-6075 online; ISSN 2615-6946 print

@UWG Press, 2018

OJS http://publishing-widyagama.ac.id/ejournalv2/index.php/jsed/
}

increased. BAPPENAS data production (2016) show that the production of major food commodities in Indonesia such as rice, corn and soybeans and meat and fish have increased. However, the balance between production and consumption of some food commodities (such as beef, soybeans and shallots) are negative. In addition, this food sector is also faced with major problems in the form of expensive and volatile prices.

In achieving food security with various conditions faced, the government's efforts are contained in Law No. 18 of 2012 concerning Food. The Act states that to achieve food security, three main issues that should be addressed are: (1) the realization of food availability based on the optimal utilization of local resources carried out by diversifying food and prioritizing domestic food production, (2) the realization of food affordability from physical and economic aspects are carried out 
through the management of supply stabilization and prices of staple foods, management of staple food reserves, and distribution of staple foods, and (3) the food utilization or food and nutrition consumption will produce quality human resources as one of the determining factors of development success. This is done through the fulfillment of a variety of food intake, balanced nutrition, food safety, food quality and food nutrition requirements.

As a follow-up and elaboration of Law No. 18 of 2012, the Food and Nutrition Strategic Policy (KSPG) is a common platform for stakeholders in the field of food and nutrition in its role and efforts to contribute optimally in food and nutrition development. In the KSPG, it was stated that the strategic food policy objectives to be achieved were: (1) increasing food availability through increasing domestic production, developing food reserves, regulating food trade based on national interests, and developing local and processed food production, (2) strengthening food affordability through efficiency in marketing facilitation, food logistics system, stabilization of food supply and prices, handling emergency food insecurity, and food assistance for poor families, (3) developing food utilization through the pattern of promoting food consumption, developing diversified food consumption based on the local food, improving nutrition community, and enhancing the security of fresh and processed food, and (4) strengthening food institutions and coordination of food security through synergy and involvement program of all stakeholders in the development of food and nutrition as well as the policy support of ministries / institutions. However, to achieve these objectives there are various problems that need to be solved.

Dealing with various food issues and problems, the role of research and development institutions such as the Indonesia Institute of Sciences (LIPI) is needed. LIPI as a government $R \& D$ institution is demanded not only to produce knowledge, but also is expected to play an active role in solving various problems of the nation including in the field of food security. The results of the evaluation of LIPI's activities show that it has produced significant and strategic research outputs. However, a few of them have been successfully implemented to solve food problems. Therefore, a study is needed so that the
LIPI research program in the future will produce more research outputs that play a role in providing solutions in this food sector. For this reason, it is necessary to conduct a Research Priority Setting (RPS) study. This RPS is an important step for planning research efficiently. RPS can help the decision-making process in the research area about what is invested, where to invest, when to invest, and how much to invest. In other words, RPS is an optimal approach to allocating research resources (Braunschweig, 2000). In addition, the RPS approach can improve the efficiency and credibility of decision makers in the research field. The purpose of this RPS study is to provide direction so that LIPI research in the future can contribute more to solving problems in the food sector.

The Research Priority Setting (RPS) is followed because of the rapid development of science and technology and its impact on the social and economic of the community. Grebenyuk et.al (2016) explains that today research activities are growing in scale, have inter-disciplinary nature and global coverage; the impact on global innovationbased development is also increasing. Despite significant growth of $R \& D$ expenditures in developed countries, none of them is capable of conducting fully-fledged research covering the whole range of subject areas. Therefore, setting sound priorities for science, technology, and innovation (STI) activities becomes particularly important since they determine the prospects not only for scientific but also socio-economic development. Most developed countries have been working on setting STI priorities for quite some time, the latter providing the basis of their STI policies. Many countries are also traditionally working on setting and regularly updating thematic priorities which include specific S\&T fields investing in which it can potentially bring the biggest social and/or economic effects in the medium to long term. A sufficiently widely articulated range of social and/or economic objectives accomplished by orienting science and technology development accordingly is obvious in such priority-setting exercises.

The Research Priority Setting (RPS) is an interpersonal activity that aims to select topics and or key choices of questions to be examined. Priority settings themselves are related to limited resource 
management. RPS is very important to understand development challenges and opportunities, to understand the organization and research institutions involved, where these areas are related to issues, and identify knowledge gaps with potential contributions that can be generated. RPS is defined as a collective activity for deciding which uncertainties are most worth trying to resolve through research; uncertainties considered may be problems to be understood or solutions to be developed or tested; across broad or narrow areas (Sandy Oliver ).

In practice, questions often arise about the difference between RPS and foresight activities. (Gavigan \& Forschung, 2001) defines foresight as a series of systematic, participatory processes, future intelligence gathering and long term vision building process in the aim of forming strategies, decisions and implementation at this time. Regarding foresight, Harper (2013) defines foresight as one of the collective approaches in exploring, anticipating and shaping the future. Foresight itself has been applied in various matters at international, national and regional levels. In the process, foresight involves many actors, as many as possible involving relevant stakeholders to provide the right picture and strategy. In addition, foresight also consists of a combination of activities such as panels, workshop scenarios, brain-storming, consensus building, horizon scanning and trend analysis (Harper, 2016).

Meanwhile, the priority setting can be defined as a negotiation process among related parties such as the public and private sectors and other stakeholders to find common ground and form strategies (OECD, 2012). Priority settings themselves are basically related to the allocation of resources in achieving the desired goals (OECD, 2010). In general, RPS is carried out implicitly as one of the foresight process series. (Popper Villarroel, Keenan, Miles, Butter, \& Sainz, 2007) states that the purpose of foresight generally revolves around: (1) fostering science, technology and innovation (STI) cooperation (2) orienting policy and decisions (3) recognizing key barriers and drivers of STI (4) encouraging strategic and futures thinking (5) supporting the STI strategy and priority setting (6) identifying research / investment opportunities (7) generating vision and images of the future (8) helping to cope with "Grand Challenges" and (9) triggering actions and promoting public debate. This is done by several developed and developing countries such as Germany, Japan, UK, China, Korea etc. In these countries the RPS is generated based on large-scale foresight projects involving all sectors of science and technology (Harper, 2013). Foresight conducted by Japan continuously since 1960 also issued a list of priority research areas and a list of key technologies. China and Korea also determine a list of important technologies based on DelphiBased Foresight that are carried out periodically. Germany also does technology foresight in analyzing the potential and demand for research and technology.

The increasing need to determine priority areas in conducting research, especially related to the efficiency and effectiveness of resources makes priority setting studies conducted explicitly (Drilhon, 1991) apart from a series of foresight activities. Current Science and technology ( $\mathrm{S} \& \mathrm{~T}$ ) priority settings are also carried out at various levels, including policy levels that are generally carried out by the government, strategic levels (generally funding agencies) and operational levels (generally carried out by R \& D institutions) (Glod, Duprel, \& Keenan, 2009). The new European Horizon 2020 Research and Innovation Framework Program (Zygierewicz, 2017) is a program that uses the Foresight methodology in determining and implementing priorities at the European Commission level. Glod et al., (2009) also mentions that basically $\mathrm{S} \& \mathrm{~T}$ priority settings also determine priorities in several other related matters, such as fields of science, industrial areas, technology areas, research facilities, types of research conducted by $R$ \& $D$ institutions and others.

The Delphi method is used in this RPS study. It is a suitable method to be applied in LIPI, whose researchers are very diverse because this method allows many researchers in this study. This method is a group process that is used to obtain written responses from several individuals. The process is intended to gather opinions from a number of individuals in order to improve the quality of decision making. In its application in the company, the Delphi process is carried out by distributing 
questionnaires sequentially to stakeholders and experts in the internal company to find out the initial state of the company's human resources, as well as knowing the criteria that affect the management of the company in making a policy in terms of fulfillment human resource needs of the company, so that qualitative data are obtained for later weighting processes.

Generally the experts involved in the delphi process are people who have expertise in the area in question or who will be assessed. Existing experts do not know one another until they are brought together in the final stages of the implementation of the Delphi method (Linstone \& Turoff, 1975). Delphi does not require direct meetings (face to face), and this is useful for involving experts, users, resource controllers, or administrators who cannot come together. Delphi allows people to list without using names, but it prevents domination by certain individuals. Because of its nature, it is possible to gather opinions from people who are hostile to each other, or where the style of individual personality will damage in a meeting.

The process of implementing the delphi method that is now commonly done is a method / version (Linstone \& Turoff, 1975) "Paper and Pencil Version", where in this method a team is formed to design a questionnaire that will be submitted to experts (group respondents). After all answers from the questionnaire are obtained, each respondent is given the opportunity to re-evaluate their answers. After that, the team concludes the results of the answers obtained. Based on these conclusions, the team designed the next step questionnaire to be re-submitted to the respondent group. The Delphi method like this is also known as "Conventional Delphi".

This study also use roundtable discussion techniques that are used to build consensus as an effort to identify problems and find solutions in the relationship between formal decision makers such as the government, and other social sectors such as environmental groups, communities and other groups. The Roundtable is not a general meeting, but a meeting or discussion focused on specifically exploring to identify existing or new issues so that they can be used to explore solutions, find actions and develop strategies. Therefore, this technique is very suitable to use in this RPS study.

Roundtable is a discussion that directs the opportunity of all participants informally to discuss issues related to or related to their business processes with a formal agenda, discussing the key points of the issue to be explored (American Pediatric Surgical Nurses Association, 2014) involving facilitators and other equipment. According to (Ashton, de Angelis, \& Graf, 2011), roundtable discussion is a discussion activity that debates issues and aims to create a win-win situation. Discussions in the roundtable involve several participants, namely business people, local leaders, workers, environmental activities, members of community groups or communities, or figures that fit the needs.

\section{RESEARCH METHOD}

This study was started from the activity stage to identify uncertainty topics, issues, questions or problems that need an attempt to be solved through a research. This identification activity is carried out through a round table discussion involving stakeholders. At this stage, the research team presented various issues to be confirmed, detailed and completed in the round table discussion to get strategic issues that need to be a concern for LIPI in developing its research program.

The next stage is the determination of research prioritizing the leading LIPI research program in the next five years (2020 - 2024) to provide solutions to the topics, issues, uncertainty questions or problems that have been identified. This stage was carried out through the process of using the Delphi method (assessment according to the Expert Council) in two rounds. The outline of the flow of this study can be illustrated in the following chart.

The first round of Delphi was started by searching ideas of LIPI experts about the research that needs to be done in the next five years to provide solutions to the uncertain topics, issues, or questions that have been identified from the previous stage. Furthermore, in the first round of the Delphi, the assessment was conducted by the Expert Board to assess the level of attractiveness of the research proposed by experts from the results 
of the ideas searching based on criteria: its potential to answer the issue and its contribution to the development of science and technology. The results of this first phase assessment are proposals for the research that will be prioritized in the LIPI research program in the next five years (20202024).

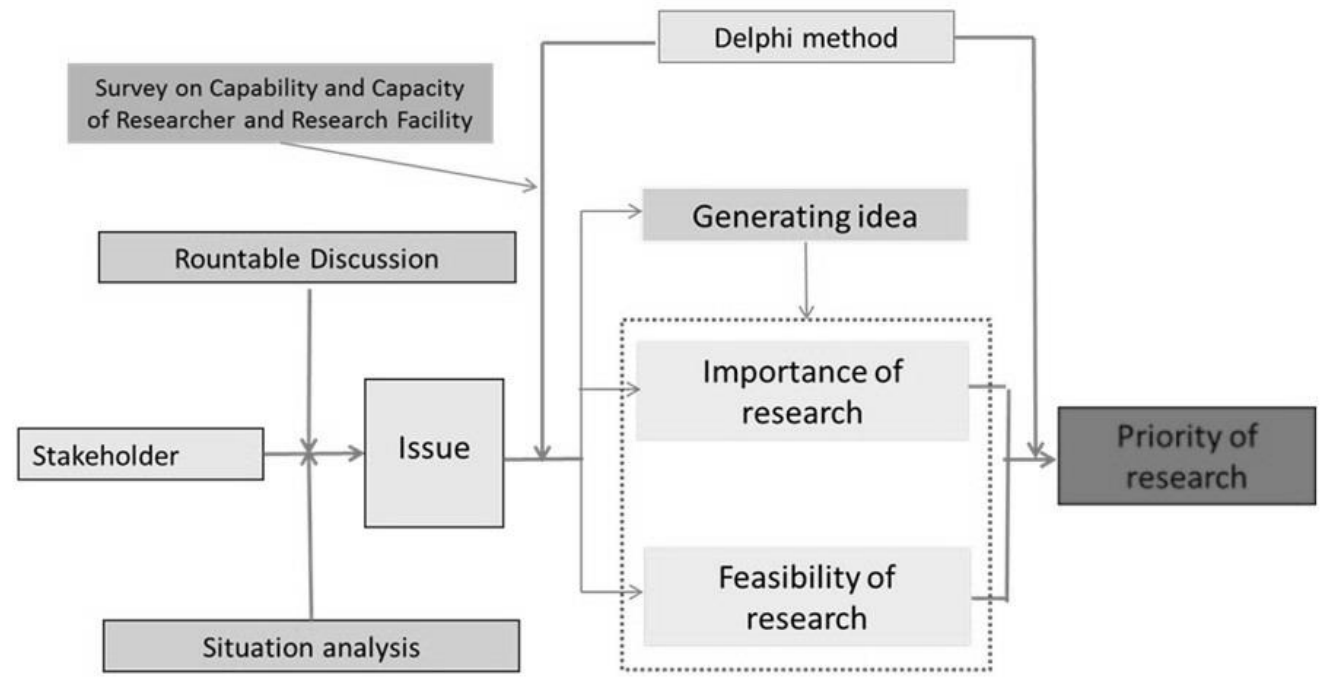

Figure 1. Flow of Study

In the second round of Delphi, it was conducted to assess LIPI's R \& D capabilities (feasibility) to carry out proposals for the research that would be prioritized in terms of the availability of expertise of the researchers and the availability and suitability of the $R \& D$ facilities and infrastructure. The complete results of these two delphi rounds are as follows:

1. Researches with high attractiveness and feasibility. This research topic group should be the main priority of the LIPI research program for the next five years;

2. Researchs with high attractiveness value, but the value of its feasibility is low. This research group needs to be studied further to determine whether LIPI needs to increase $R$ \& $D$ capabilities in the research area;

3. Research topics with low attractiveness value, but the value of the feasibility is high. This indicates that LIPI has a high R \& D capability, but the level of importance of this research topic is low. Thus, LIPI should consider transferring this R \& D capability to research that has a high level of importance;

4. Research with low attractiveness and low value of feasibility. This research group should not be a priority in LIPI's flagship research program

From the results of the roundtable discussion identified, there were 49 strategic issues in the field of food security that needed solutions through research and development activities. Meanwhile, from the LIPI researchers' identification results, there were 77 researchers who had experience in conducting research related to the food sector. Questionnaires to capture research ideas that can provide solutions to 49 strategic issues were given to all of the researchers and 57 researchers including returning questionnaires and giving research topic ideas for the next five years. There are totally 171 research topics from the results of ideas searching.

After checking the incoming research topics, several research topics were combined with other research topics because the research topics were considered inappropriate and / or had a high 
resemblance to other research topics. From the results of the checking, 157 research topics were obtained, which were then assessed by the Expert Council for the atractiveness and feasibility level. The details of the number of research topics are shown in Table 1 below. The evaluation of structural model is pointed to know the effect of one independent latent variable to dependent latent variable. There are two parameters to test causal correlation between two latent variables. The coefficient of determination (R2) for the dependent construct, the path coefficient and or t-value of each path are for the significant test between construct in the structural model.

\section{RESULT AND DISCUSSION}

From the results of the roundtable discussion identified, there were 49 strategic issues in the field of food security that needed solutions through research and development activities. Meanwhile, from the LIPI researchers' identification results, there were 77 researchers who had experience in conducting research related to the food sector. Questionnaires to capture research ideas that can provide solutions to 49 strategic issues were given to all of the researchers and 57 researchers including returning questionnaires and giving research topic ideas for the next five years. There are totally 171 research topics from the results of ideas searching.

After checking the incoming research topics, several research topics were combined with other research topics because the research topics were considered inappropriate and / or had a high resemblance to other research topics. From the results of the checking, 157 research topics were obtained, which were then assessed by the Expert Council for the atractiveness and feasibility level. The details of the number of research topics are shown in Table 1 below.

Table 1 shows that diversifying food consumption is the most interesting issue for LIPI researchers. This can be seen from the large number of research topics proposed by researchers to provide research-based solutions related to the food issues. The next issue that attracts many LIPI researchers is the issue of food availability, followed by the issue of climate change and mitigation and the issue of food and agriculture systems (on-farm and off-farm). This fact can also indicate that food research at LIPI tends to be done a lot on these issues. Thus, it can be assumed that LIPI has competence in these areas.

Table 1. The distribution of research topics number from ideas searching based on issues

\begin{tabular}{lc}
\hline Food Issues & $\begin{array}{c}\text { Number of } \\
\text { research } \\
\text { topics }\end{array}$ \\
\hline 1. Food Availability & $\mathbf{9 9}$ \\
- Climate Change and Mitigation & 26 \\
- Food Availability & 34 \\
- Food and Agriculture Systems (on-farm & \\
and off-farm) & 23 \\
- Germplasm & 9 \\
- Institutional & 6 \\
- Data and Information & 1 \\
2. Affordability / Food Accessibility & $\mathbf{5}$ \\
- Food Price Stability & 0 \\
- Food Affordability & 0 \\
- Distribution and logistics infrastructure & 4 \\
- Data and Information & 1 \\
3. Food Consumption and Nutrition & $\mathbf{5 3}$ \\
- Food Safety & 8 \\
- Diversification of Food Consumption & 39 \\
- Nutrition Improvement & 3 \\
- Food Sanitation & 3 \\
- Data and Information & 0 \\
\hline
\end{tabular}

Furthermore, table 1 also shows that LIPI researchers are less interested in the issue of affordability / food accessibility. This fact can be seen from the lack of researchers who provide input on research ideas that need to be carried out by LIPI to answer this strategic issue, even none of the researchers proposed research topics on the sub-issues of food price stability and food affordability. This fact also indicates that so far LIPI has not done much research on affordability / food accessibility.

In addition, to determine which research topics should be prioritized by LIPI in the next five years. It will be carried out assessment of the atractiveness and the ability of LIPI to conduct R \& $D$ on each research topics proposed by the researchers. The level of attractiveness is assessed based on its potential in answering issues and its contribution to the development of science and technology, while the level of ability in conducting $R \& D$ is assessed by the availability of researchers, facilities and infrastructure. This assessment was carried out by five LIPI expert boards selected based on the consideration of competence and experience in researching and pursuing research in 
the field of food. Each expert council assigns scores between 1 (none at all) to 10 (very large) or 0 (if it is not assessed) on each research topic. However, the discussion of the Expert Council decides that the assessment is carried out by giving odd numbers $(1,3,5,7$ or 9$)$. If the expert council feels that it cannot provide an assessment due to lack of information and knowledge possessed on a particular research topic, the expert board can give a value of 0 .

The results of the attractiveness assessment research topics and the capacity of $R \& D$ to do the research are shown in two-dimensional graphs, where R \& D capabilities as the X-axis and level of attractiveness as the $Y$-axis and the average line in both variables become quadrant boundaries. The results of the respondents' assessment showed that the average value of the atractiveness of all topics was 5.29 and the average value of the R \& D ability level as seen from the availability of researchers (5.64) was greater than the average value of availability of facilities and infrastructure (5.25). Based on these average values, the research topic was mapped in 4 quadrants, namely:

1. Quadrant I: the value of attractiveness and R \& $\mathrm{D}$ capability is small (below the average line). Research topics in quadrant I do not need attention to be LIPI's priority.

2. Quadrant II: the value of the atractiveness is small, but the value of the R\&D capability is large (above the average line). This indicates that LIPI has a high R \& D capability, but the importance level of these research topics is low.

3. Quadrant III: the value of attractiveness is large, but the value of $R \& D$ capability is small. This indicates that there are important research topics to do, but LIPI does not have sufficient capacity to conduct R \& D on these topics.

4. Quadrant IV: the value of the level of attractiveness and R\&D capability is high. The research topics in this quadrant become research topics that should be prioritized by LIPI for the next five years.

The results of the research topic mapping based on the level of attractiveness and R \& D capability show that most research topics are including in Quadrant IV, which is 33\% when viewed based on the level of attractiveness and availability of researchers and $32 \%$ when viewed based on the level of attractiveness and availability of facilities and infrastructure.

Figure 2 and 3 show a map of research topics based on quadrants (level of atrractiveness and R \& D capability). This map is the basis for determining food research priorities which should be carried out by LIPI in the next five years. Then the group of research topics with the highest scores were analyzed and discussed by the Expert Council to be chosen as the LIPI priority research for the next five years and formulated for implementation.

Figure 2 shows a map of the research topic based on the level of attractiveness and the availability of researchers described in the quadrant. The figure shows that research topics that have a high level of attractiveness and $R$ \& $D$ capabilities form several research topic clusters, which are related to Functional Food, Biological Organic Fertilizers, Local Food Materials, and Germplasm. In addition, there are also research topics with high importance (above 6.5) but the availability of researchers is not adequate, namely the development of food or technology in order to respond to climate change. This topic is important to be done by LIPI because it has high potential in answering issues and contributing greatly to the development of science and technology. However, LIPI does not have sufficient availability of researchers both quantity and quality for these topics.

Likewise, when viewed based on the level of attractiveness and availability of facilities and infrastructure, it shows the tendency of research topics including in Quadrant IV to group several research topic clusters similar to Figure 2, namely the Biological Organic Fertilizer, Plasma Nutrition, Local Food, Functional Food cluster and Modern Agriculture. Furthermore, from the second picture above shows the topics of functional food research that have a high value of attractiveness. This means that the research topic is important to be carried out by LIPI in the next five years. However, if it is seen from the ability of the Research Institute to conduct research, there are important notes that need to be considered by LIPI. In conducting functional food research, the availability of LIPI researchers is considered to be adequate but it is still considered inadequate in terms of availability of facilities and infrastructure 


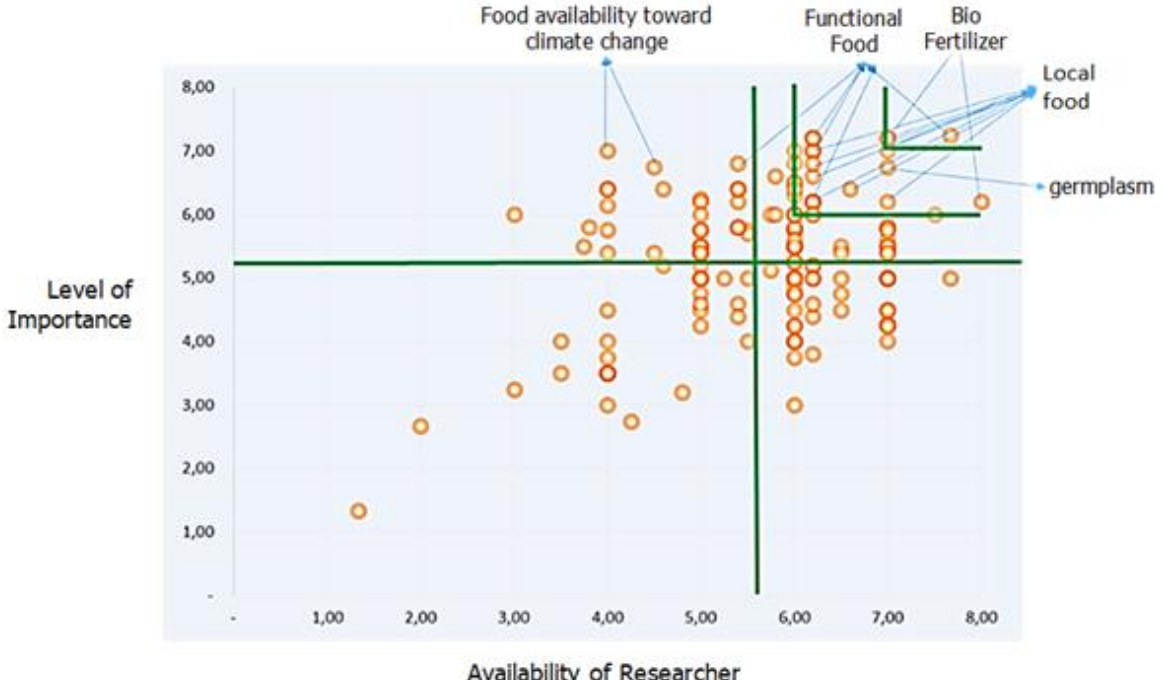

Figure 2. The map of food research topics based on availability of researcher

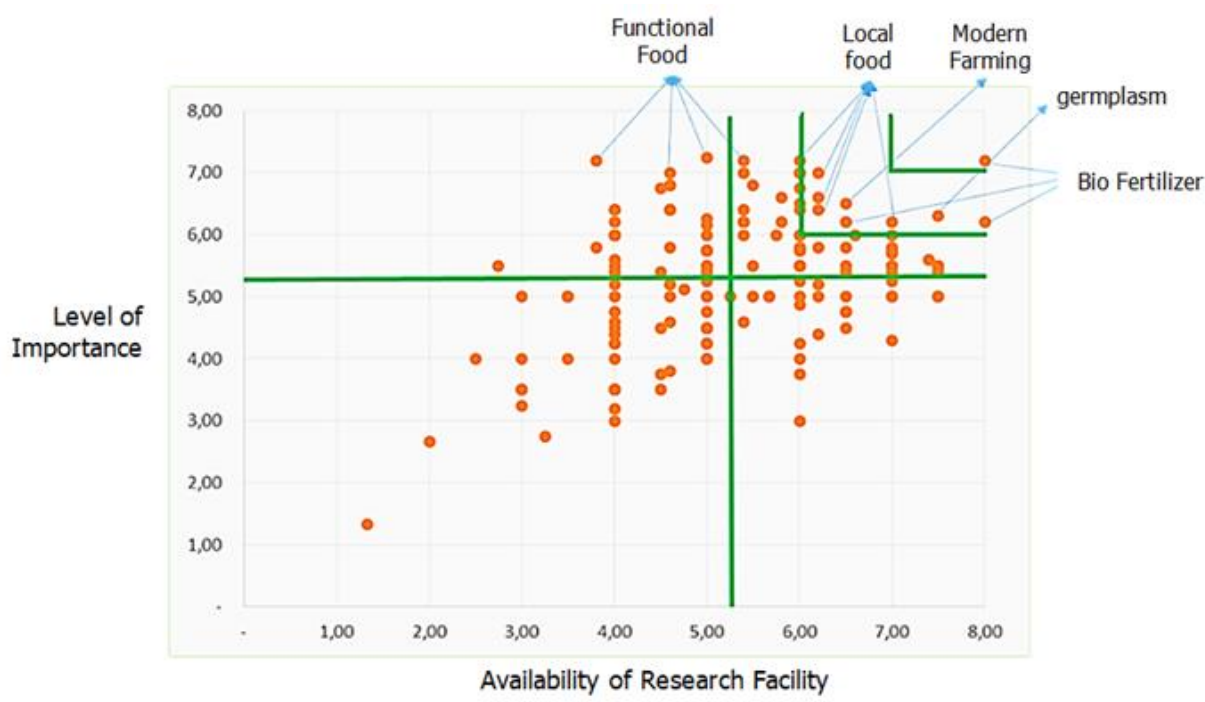

Figure 3. The map of the topic of food research based on research facility

Based on the results of the assessment of the attractiveness and capacity level of the researchers and the results of the FGD, the Board of Experts agreed that in the context of addressing the issue of food security, research at LIPI in the future should focus on two main issues, namely: food availability and food consumption (Figure 4). In the issue of food availability, LIPI can contribute through a research related to climate change mitigation for food availability and an increase of food productivity. Meanwhile, to answer the issue of food consumption, LIPI should be able to contribute to the development of healthy and nutritious food products and downstream food research until it is accepted by the community. This is a basic concept for LIPI to determine food sector research priorities in the future. 
Furthermore, based on the concept and the results of the research topic mapping according to the level of attractiveness and R \& D capabilities, the Board of Experts agreed that for the next five years LIPI research priorities in food can be focused on biological organic fertilizer development research, local food ingredients, germplasm, functional food and modern agriculture. Research priorities for LIPI food field in the next five years are explained below.
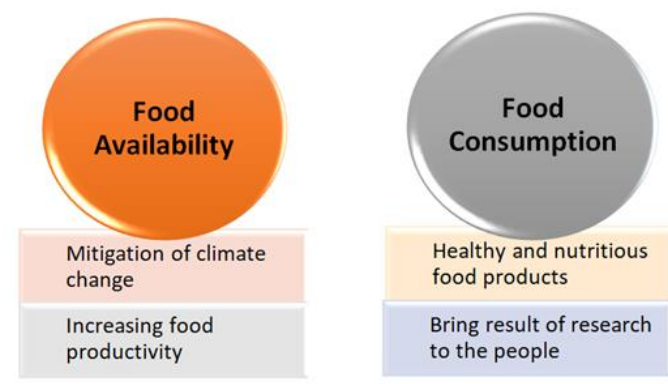

Figure 4. The concept of LIPI's research on food in the future

\section{1) The Development of Biological Organic Fertilizer}

Until now, LIPI is recognized to have high competence in conducting research and development in several strategic sectors including food. One of LIPI's research and development activities that has been carried out for more than five years is biological organic fertilizer. LIPI has succeeded in building competencies in the field of biological organic fertilizer research. In recent years, LIPI has succeeded in developing biological organic fertilizer, where the results have been disseminated to various provinces in Indonesia. This biological organic fertilizer development is still important to be carried out by LIPI in the future.

Microbes that are microbial candidates for biological organic fertilizer agents (Rizobakteri boosting plant growth) are generally living things that are very responsive, clever, and very efficient in responding to changes in the environment. The life includes the impacts of global climate change and environmental changes due to ecological processes or human activities. For this reason, the next five years the development of biological organic fertilizer needs to be directed towards the purpose of disaster mitigation due to climate change. The occurrence of extreme climate change during this time and excessive use of chemical fertilizers has an impact on the decline in soil productivity significantly. The use of biological organic fertilizer from LIPI research results both alone and mixed with chemical fertilizers, and has been proven to improve soil structure and increase agricultural productivity. For that reason, in the next five years LIPI still needs to conduct research for the development of biological organic fertilizer which is intended as a disaster mitigation effort, so that the productivity of the land will be maintained and will have positive implications for food availability in the end.

The superior microbial properties of biological organic fertilizer agents in overcoming stress of high salt content on agricultural land due to sea water intrusion, drought stress or flooded, pest attack which are resistant to controlling toxins and becomes the basis of future biological organic fertilizer research and development. On the other hand, an increase in organic-based industries, including those from the marine industry, is also increasing parallel produces large amounts of waste, so it needs to be wisely overcome to produce products of high economic value, for example, as a material or media for making biological organic fertilizer. To improve quality and efficiency further, the modern technology approach through molecular technology and sophisticated machinery is absolutely necessary although the community implementation should be developed that is practical, effective and available and affordable raw materials remain a top priority.

In order to develop biological organic fertilizer for the purpose of disaster mitigation, there are several steps that need to be carried out, namely:

a. Exploration, screening and molecular characterization of superior microbial starter formula biological organic fertilizer candidates for special needs based on the ecosystem conditions, stress, and plant commodity groups.

b. The development of biological organic fertilizer formulas is based on organic materials of agro waste, livestock and marine products and development of production fermentation technology.

c. The starter formula test and the formula for biological organic fertilizer on the demfam scale 
and the wider community are based on the specific commodities and ecosystems.

d. Dissemination and commercialization of starter formulas and the formula of the regional scale and community scale of biological organic fertilizer are based on specific commodities and ecosystems.

\section{2) The Development of Local Food Materials}

So far LIPI has had a good track record in researching local food development. LIPI has the ability to identify to its development. Until now, for the development of local foodstuffs, such as tubers and bananas, LIPI has been able to do nursering and processing to produce products. For the next five years, in terms of local food development, LIPI needs to make downstream efforts from what has been developed, so that it can be accepted by the community. The intended downstream includes social and institutional studies, as well as dissemination and education to the community, so that local food materials developed by LIPI can be truly accepted and consumed by the community as a form of food diversification.

For the next five years, LIPI also still needs to develop local food ingredients but it focuses on carbohydrate food sources. Local food that is developed should be nutritious and have high economy. For this reason, it is necessary to carry out several stages, namely characterization, cultivation and processing. Local food material development also needs to be linked to its future development as functional food.

\section{3) The Development of Germplasm}

The number of local plants that are increasingly extinct, livestock and local fish, and microbes that have not been explored encourage LIPI to maintain research in the field of biodiversity. One important thing is the development of the germplasm collection to become one of LIPI's flagship researches in the field of food. LIPI is recognized as having competent abilities in this field compared to other institutions. The development of germplasm is still considered to be an important thing to be done by LIPI because of its high potential in answering food issues and its large contribution to the development of science and technology. However, for the next five years the development of germplasm carried out by LIPI should be directed to the developing functional food, anticipating climate change, increasing productivity and diversifying food. For this reason, LIPI needs to carry out several important stages, namely in-depth characterization of germplasm nutrition as food ingredients for its cultivation or domestic efforts, and product diversification so that it is interested by the community.

\section{4) The Functional Food Development}

The development of functional food is considered as research that has high potential in answering issues and contributing greatly to the development of science and technology today. In relation to the resources to conduct research in this field, LIPI is considered to have adequate researchers both in terms of quantity and quality. Nevertheless, LIPI is considered not to have adequate infrastructures to conduct this research. Therefore, to encourage this research in the next five years, LIPI needs to strengthen the infrastructures that support the development of functional food.

In addition, there are several important things that should be the basis for the research on functional food development at LIPI five years later. The development of functional food at LIPI should come from raw materials that are already available and ready to use. That functional food is developed from raw materials that have been researched and developed by LIPI, such as mocaf and cassava (there are seeds and production technology), tacca, arrowroot, uwi, and banana (already cultivated). Thus, the results of functional food research can be an innovative product accepted by the community and it is necessary to pay attention to the availability of raw materials (it needs to be considered in determining raw materials) and need to be equipped with a study of techno-economics.

\section{5) The Development of Modern Agriculture}

The development of modern agriculture is one of the researches that needs to be prioritized by LIPI for the next five years. This needs to be done in order to increase food availability through increasing productivity and food diversity. Regarding to the development of modern agriculture in the next five years, the focus of LIPI's research includes institutional studies, development 
of on-farm agricultural technology, post-harvest technology, and packaging technology. The development of post-harvest technology is directed at the development of technologies aimed at harvesting, efficient technology, and drying technology. Meanwhile, the development of packaging technology is directed at developing types of packaging that are environmentally friendly, both canned and non-canned.

\section{CONCLUSION AND SUGGESTION}

Indonesia faces various issues and problems in the field of food security that require solutions through research and development activities. Issues and problems in the field of food security arose mainly due to population and national economic development increases and the existence of extreme natural phenomena which resulted in a decrease in the number of agricultural commodity production and degradation of agricultural land. The increasing number of population resulted in the increasing number of food demand. Meanwhile, national economic growth has led to a growing percentage of Indonesia's upper middle income groups resulting in changes in spending on food consumption and food consumption patterns. The percentage of consumption expenditure of carbohydrates (cereals) decreases, while the expenditure for protein consumption (meat and fish), vitamins (fruits and vegetables) and processed foods increase. However, the current condition of national food availability has not been able to compensate for these changes in needs, so that the balance sheet statistically experiences a deficit in important commodities. Global food conditions are also expected to continue to experience improvement and scarcity, so that food prices will continue to increase. Therefore, the procurement of food through imports will also be increasingly difficult.

In this study, it is identified 49 strategic issues in the field of food security that require solutions through research and development activities. As a research institute, LIPI is not only expected to play a role in the development of science, but is also required to contribute to solve these issues. The results of the screening of research ideas showed that the issue of diversifying food consumption attracted the attention of most LIPI researchers.
On this issue, there are at most a number of research topics proposed by researchers to provide research-based solutions related to these issues or problems. The next issue attracted LIPI researchers' attention was the issue of food availability, followed by the issue of climate change and mitigation, and the issue of food and agriculture systems (on-farm and off-farm). This fact can also indicate that food research at LIPI tends to be done a lot on these issues. Meanwhile, LIPI researchers are less interested in the issue of affordability or food accessibility. In this issue, there is only a few of the LIPI researchers who gave input on research ideas that need to be done by LIPI to address these strategic issues, even none of the researchers proposed a research topic on the sub-issue of food price stability and food affordability. This fact also indicates that so far LIPI has not done much research on affordability or food accessibility.

In the context of answering the issue of food security, LIPI research in the future should focus on two main issues, namely: food availability and food consumption. LIPI can contribute through a research related to climate change mitigation for food availability and an increase for food productivity. Meanwhile, to answer the issue of food consumption, LIPI should be able to contribute to the development of healthy and nutritious food products and downstream food research until it is accepted by the community.

\section{ACKNOWLEDGMENT}

We acknowledge the Center for Science and Technology Development Studies who provides resources for our research in RPS. This article is an advanced development from part of our report which is based on our findings and analysis in the research.

\section{REFERENCES}

American Pediatric Surgical Nurses Association. (2014). Kindling Synergy in Pediatric Surgical Care: Professional and Clinical Collaborative Practice-23rd Annual APSNA Scientific Conference Overview. Journal of Pediatric Surgical Nursing, 3(3), 68-71. Retrieved from https://www.nursingcenter.com/journalarticle?A rticle ID $=2582009 \& J$ Journal ID $=2419515 \&$ Issue $\mathrm{ID}=2582000$ 
Ashton, D. R. ., de Angelis, K., \& Graf, C. (2011). How to Plan, Organize, Perform, Evaluate, and Document Rountables. Retrieved from https://cocoate.com/sites/cocoate.com/files/gui de.pdf

Braunschweig, T. (2000). Priority Setting in Agricultural Biotechnology Research: Supporting Public Decisions in Developing Countries with the Analytic Hierarchy Process (No. ISNAR Research Report No. 16). Hague.

Drilhon, G. (1991). Choosing priorities in science and technology. Paris: OECD. Retrieved from https://books.google.co.id/books?id=8oclAAAA MAAJ

Gavigan, J. P., \& Forschung, E. K. G. (2001). A practical guide to regional foresight. FOREN, Foresight for Regional Development Network. Retrieved from https://books.google.co.id/books?id=sGTJGwAA CAA]

Glod, F., Duprel, C., \& Keenan, M. (2009). Foresight for science and technology priority setting in a small country: The case of Luxembourg. Technology Analysis and Strategic Management, 21(8), 933-951. https://doi.org/10.1080/09537320903262298

Harper, J. C. (2013). Impact of Technology Foresight (No. No. 13/16). Manchester. Retrieved from http://www.innovationpolicy.orq.uk.

Linstone, H. A., \& Turoff, M. (1975). The Delphi method: techniques and applications. AddisonWesley Pub. Co., Advanced Book Program.
Retrieved from https://books.google.co.id/books?id=52xHAAAA MAAJ

OECD. (2010). Priority Setting for Public Research: Challenges and Opportunities. Paris.

OECD. (2012). Meeting Global Challenges Through Better Governance: International Cooperation in Science, Technology and Innovation. Paris: Organisation for Economic Cooperation and Development. Retrieved from https://books.google.co.id/books?id=SVj5uQEA CAAJ

Popper Villarroel, R., Keenan, M., Miles, I., Butter, M., \& Sainz, G. (2007). Global Foresight Outlook 2007: Mapping Foresight in Europe and the rest of the World. The EFMN Annual Mapping Report 2007. (E. European Commission, Ed.). Manchester: The University of Manchester. Retrieved from https://www.research.manchester.ac.uk/portal/ en/publications/global-foresight-outlook-2007mapping-foresight-in-europe-and-the-rest-ofthe-world-the-efmn-annual-mapping-report2007(fef02bbe-f742-4077-a4e9b069c2985557)/export.html\#export

Zygierewicz, A. (2017). Horizon 2020, EU Framework Programme for Research and Innovation: European Implementation Assessment. EPRS, European Parliamentary Research Service. Retrieved from https://books.google.co.id/books?id=CqINswEA CAAJ 